\title{
Assessment of air pollution in residential areas of Kinondoni municipality in Dar es Salaam City, Tanzania
}

\author{
Msafiri M. JACKSON \\ Department of Environmental Engineering, Ardhi University, P.O. Box 35176, Dar es Salaam, Tanzania. \\ E-mail: msafiri@uclas.ac.tz,Tel: 255-744263995, Fax: 255-222775391
}

\begin{abstract}
The quality of the ambient air at residential areas has been assessed for Kinondoni Municipality in Dar es Salaam City. Three air pollutants namely Nitrogen dioxide $\left(\mathrm{NO}_{2}\right)$, suspended particulate matter (SPM), and particulate lead $(\mathrm{Pb})$ were measured in Mikocheni, Kijitonyama, Sinza, and Manzese. Saltzman, filtrations, and Atomic Absorption Spectrometric methods were correspondingly used for analysis of $\mathrm{NO}_{2}, \mathrm{SPM}$, and particulate lead. Results have shown that with exception of $\mathrm{NO}_{2}$, the other pollutants were present at levels above the WHO guidelines. The SPM concentration varies from $418.7 \mu \mathrm{g} / \mathrm{m}^{3}$ to $804.0 \mu \mathrm{g} / \mathrm{m}^{3}$ while the WHO guideline value is $230 \mu \mathrm{g} / \mathrm{m}^{3}$. The particulate lead range from 7.4 to $12.0 \mu \mathrm{g} / \mathrm{m}^{3}$ exceeding the quarterly WHO standard of $1.5 \mu \mathrm{g} / \mathrm{m}^{3}$. Hourly average nitrogen dioxide concentration ranges from $16.0 \mu \mathrm{g} / \mathrm{m}^{3}$ to $74.0 \mu \mathrm{g} / \mathrm{m}^{3}$, which is below the WHO guidelines value of $200 \mu \mathrm{g} / \mathrm{m}^{3}$. The carcinogenic risk assessment due to particulate lead pollution was undertaken considering people who spend most of their time in the residential areas. The additional unit risk realised was $78.8 \times 10^{-6}$ for adults and $25.1 \times 10^{-6}$ for children, both scenarios showing additional risk higher than the United States of America Environmental protection agency (USEPA) acceptable risk of $1 \times 10^{-6}$. The obtained additional unit risk is equivalent to 48 people getting cancer out of 606767 exposed adult population and 12 children out of 476746 exposed children in Kinondoni Municipality. From these results it can be concluded that Kinondoni municipality dwellers, are living in hazardous atmospheric environments.
\end{abstract}

(C) 2009 International Formulae Group. All rights reserved.

Keywords: Particulate, lead, nitrogen dioxide, residential, carcinogenic risk assessment, air pollution.

\section{INTRODUCTION}

Most of the previous air pollution studies conducted in Dar es Salaam focused on traffic air pollution. These studies therefore were conducted on the roadside, road junction, and bus stations and quantified air pollutants such as sulphur dioxide $\left(\mathrm{SO}_{2}\right)$, nitrogen dioxide $\left(\mathrm{NO}_{2}\right)$, suspended particulate matter (SPM), and particulate lead $(\mathrm{Pb})$ (Jackson 2005a, Jackson 2005b, Kamuzora, 2003). Air pollution studies on residential areas have rarely been conducted in Tanzania. On the other hand, a high correlation has been observed between outdoor nitrogen dioxide concentration and sudden infant syndrome in the State of California, USA (Klonoff-Cohen et al., 2005). Children and senior citizens are the most vulnerable groups of the population to air pollution at the residential areas, as they spend most of their time at home (Jackson and Semiono, 2005). The current study will assess levels of $\mathrm{NO}_{2}$ and SPM.

Lead is added to fuel as an antiknock compound or as a metallic lubricant. Lead is a probable carcinogenic compound (LaGrega et al., 1994). Leaded petrol has been banned for use in Tanzania since year 2003. The current regulation on lead pollution control focuses on leaded petrol with no consideration of other sources of lead pollution such as industrial oil and paints. This study intends to establish the current levels of particulate lead 
pollution in Kinondoni municipality in an attempt to gauge the effectiveness of the ban of leaded petrol and its enforcement strategies, and the contribution of other lead sources to pollution.

This study, besides providing data on level of air pollutants in Kinondoni municipality in Dar es Salaam City, also provides carcinogenic risk assessment results. Kinondoni Municipality which is the study area has a total population of $1,083,513$ people (National Census Report, 2002). Ambient air sampling within the municipality has been carried out at Mikocheni, Sinza, Manzese and Kijitonyama. Activities practised in the area which could generate air pollutants include industries (large and small scale), construction, traffic, open burning of waste and small scale agricultural activities.

\section{MATERIALS AND METHODS}

Collection of samples was done in residential area at the following four sites within Kinondoni municipality: Mikocheni, Kijitonyama, Sinza, and Manzese (Figure 1). In every site, samples were collected at two different points. The sampling points were located in residential areas. Sampling time of
1 hour was used for $\mathrm{NO}_{2}$ in all cases. Three samples were collected in a day from these sampling points. The morning, afternoon, and evening sampling were collected between $6.30 \mathrm{~mm}$ and $8.30 \mathrm{am}, 12.00 \mathrm{pm}$ and $2.00 \mathrm{pm}$, and $5.00 \mathrm{pm}$ and $7.00 \mathrm{pm}$ correspondingly. For particulate sampling, a sampling time of 6 hours was used. This allowed a collection of two samples only in a day, as sampling was conducted in the day time only.

Gries-Saltzman method was used for sampling and analysis of $\mathrm{NO}_{2}$. The method is intended for manual determination of $\mathrm{NO}_{2}$ in the atmosphere in the concentration range of few $\mu \mathrm{g}-\mathrm{NO}_{2}$ to about $9400 \mu \mathrm{g} / \mathrm{m}^{3}$ (5 ppm) for sampling period of about 1 hour at a flow rate of 0.6 liters/minute. The method is based on specific reaction of the nitrite ion with a diazotizing-coupling reagent to form a deeply colored ozo dye, which is measured electrophotometrically. Sampling was conducted in the Fritted bubblers (absorbing reagent bottles). The $\mathrm{NO}_{2}$ in the ambient air is converted to nitrite on contact with an absorbing solution containing the diatizotizing-coupling reagent (Griess-saltzman reagent), and a stable pink colour

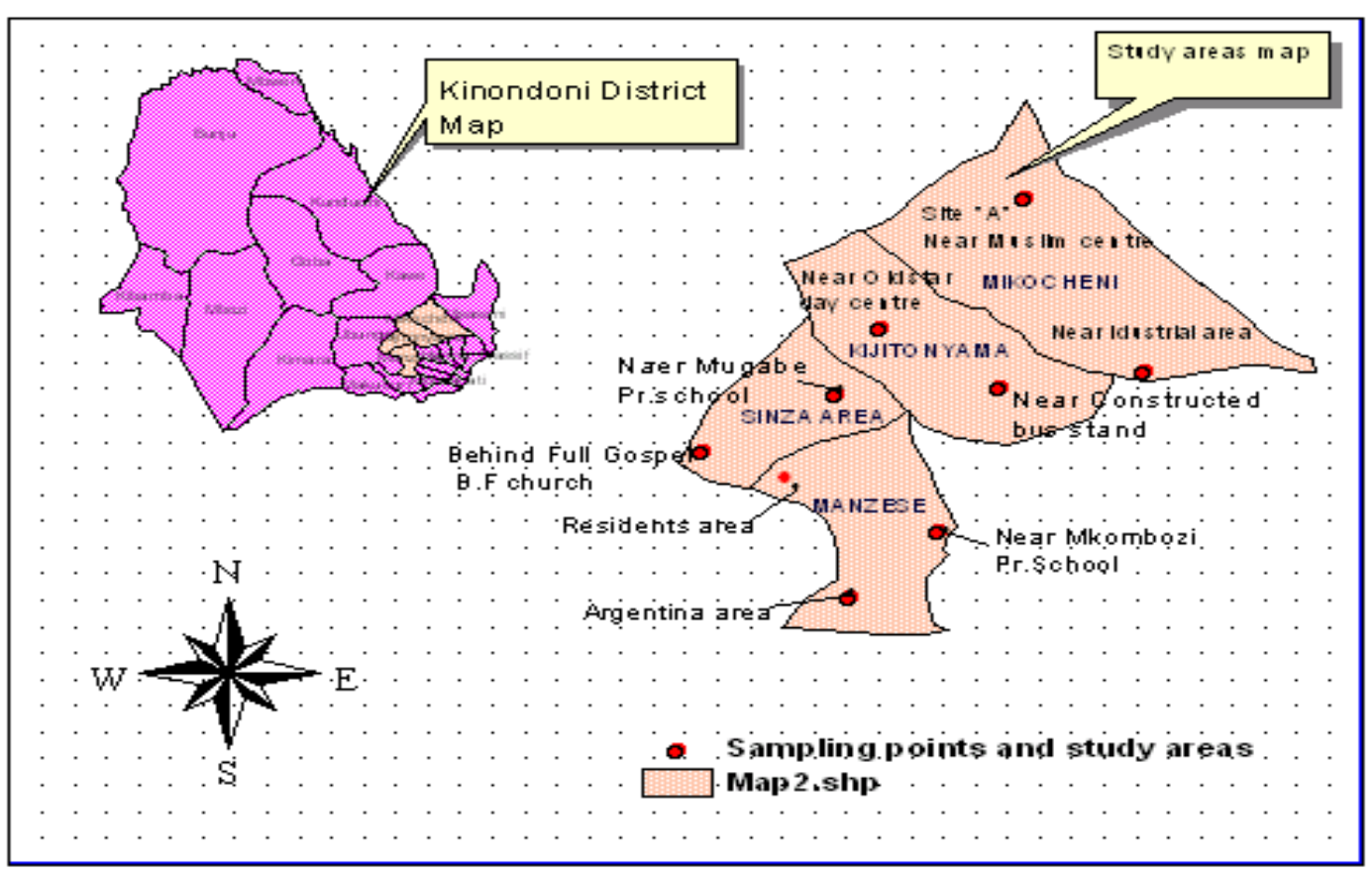

Figure 1: Sampling sites. 
is produced within 15 minutes, which is intensely measured by a spectrophotometer. Vacuum pump and filter papers were used for sampling and quantification of particulate loading in the air. The weight of the filter paper was measured prior to collection of suspended particulate matters (SPM). The filter paper was then placed in the experimental set-up using a holder. Ambient air was passed through the filter paper at a known flow rate and a time of about one hour. The weight of SPM was obtained by subtraction of the weight of the filter paper from the final weight of the filter paper and suspended particulate matters. Air sample volume is obtained by multiplying the air flow rate and the sampling time. The Suspended particulate matter concentration was then determined by simply dividing the weight of the collected SPM on the filter paper (in $\mu \mathrm{g}$ ) by air sample volume $\left(\mathrm{m}^{3}\right)$. Particulate Lead was extracted from the collected Particulate matter by digesting the filter papers with particulate matter. The Lead concentration was then measured using Atomic absorption Spectrometric method. Sampling methods, materials and analysis methods, used in this study have been used in previous studies and described in other published articles (Jackson, 2005a; Jackson; 2005b; WHO, 1976).

\section{Risk assessment}

Lead is known to adversely affect the nervous, reproductive, digestive, cardiovascular blood-forming system and the kidney (Jackson, 2005a). According to United States Environmental Protection Agency (USEPA) risk guidelines of 1986, Lead is classified under group B2 (probable human carcinogen group of substances) and from experiments done in animals, it is believed to be a carcinogenic substance with potential adverse health effects to human beings (LaGrega et al., 1994).

The environmental agent assessed in this study is Lead.

$$
\begin{gathered}
\text { Cancer risk, } R, \quad \text { is given by: } \\
R=C D I \times P
\end{gathered}
$$

where $\mathrm{P}$ is the potency factor of pollutant (can be found from literature) $(\mathrm{mg} / \mathrm{kg} \text {-day })^{-1}$, and CDI the chronic daily intake dose $(\mathrm{mg} / \mathrm{kg}$ per day).

$$
C D I=\frac{C A \times I R \times E D \times E F \times L}{B W \times A T \times 365}
$$

where: $\mathrm{CA}$ is the contaminant concentration in air $\left(\mathrm{mg} / \mathrm{m}^{3}\right)$; IR the inhalation rate $\left(\mathrm{m}^{3} / \mathrm{hr}\right)$; EF-Exposure frequency (weeks/yr); L the Length of exposure (yrs); BW the Body weight $(\mathrm{kg})$; AT the Averaging time of 70 years for carcinogens, ED the Exposure duration (hrs/wk).

Human beings are exposed to lead through three routes, namely: inhalation, ingestion, and dermal contact. In this case, exposure route considered is inhalation.

$\mathrm{PR}=\mathrm{R} \times$ Population where, PR: Population risk; R: risk.

\section{RESULTS \\ Nitrogen dioxide}

The hourly concentration of Nitrogen dioxide in air at residential areas ranges from 16 to $74 \mu \mathrm{g} / \mathrm{m}^{3}$. The observed levels are within the acceptable one-hour standard of 190-320 $\mu \mathrm{g} / \mathrm{m}^{3}$ specified by World Health Organization (WHO) guidelines (WHO, 1987). The hourly average concentrations of nitrogen dioxide for sampled sites and number of samples $\mathrm{n}$ for each site are presented in table 1 .

The overall average concentration of nitrogen dioxide for all the four sites is $46.9 \pm 19.0 \mu \mathrm{g} / \mathrm{m}^{3}$. The highest concentrations were observed in Mikocheni and Manzese areas while the lowest concentration was observed in Sinza area (Table 1). In most cases, the levels of these pollutants were higher in the morning and evening hours than in the afternoon hours (Figure 2).

\section{Suspended particulate matter (SPM)}

Average six hourly suspended particulate matter concentrations at all sites ranging from 418 to $804 \mu \mathrm{g} / \mathrm{m}^{3}$ (Table 2) were higher than the recommended values of 150$230 \mu \mathrm{g} / \mathrm{m}^{3}$ by WHO (WHO, 1987). The six hourly average concentrations of nitrogen dioxide for the two samples collected from each sites are presented in table 2 .

The overall average concentration of SPM for all the four sites is $645.3 \pm 169.3$ $\mu \mathrm{g} / \mathrm{m}^{3}$. The average SPM concentrations was slightly higher in the first six hours (morning to afternoon) sampling period than in the second sampling period (Afternoon to Evening) (Figure 3). 
Table 1: Average concentration of nitrogen dioxide $\left(\mu \mathrm{g} / \mathrm{m}^{3}\right)$.

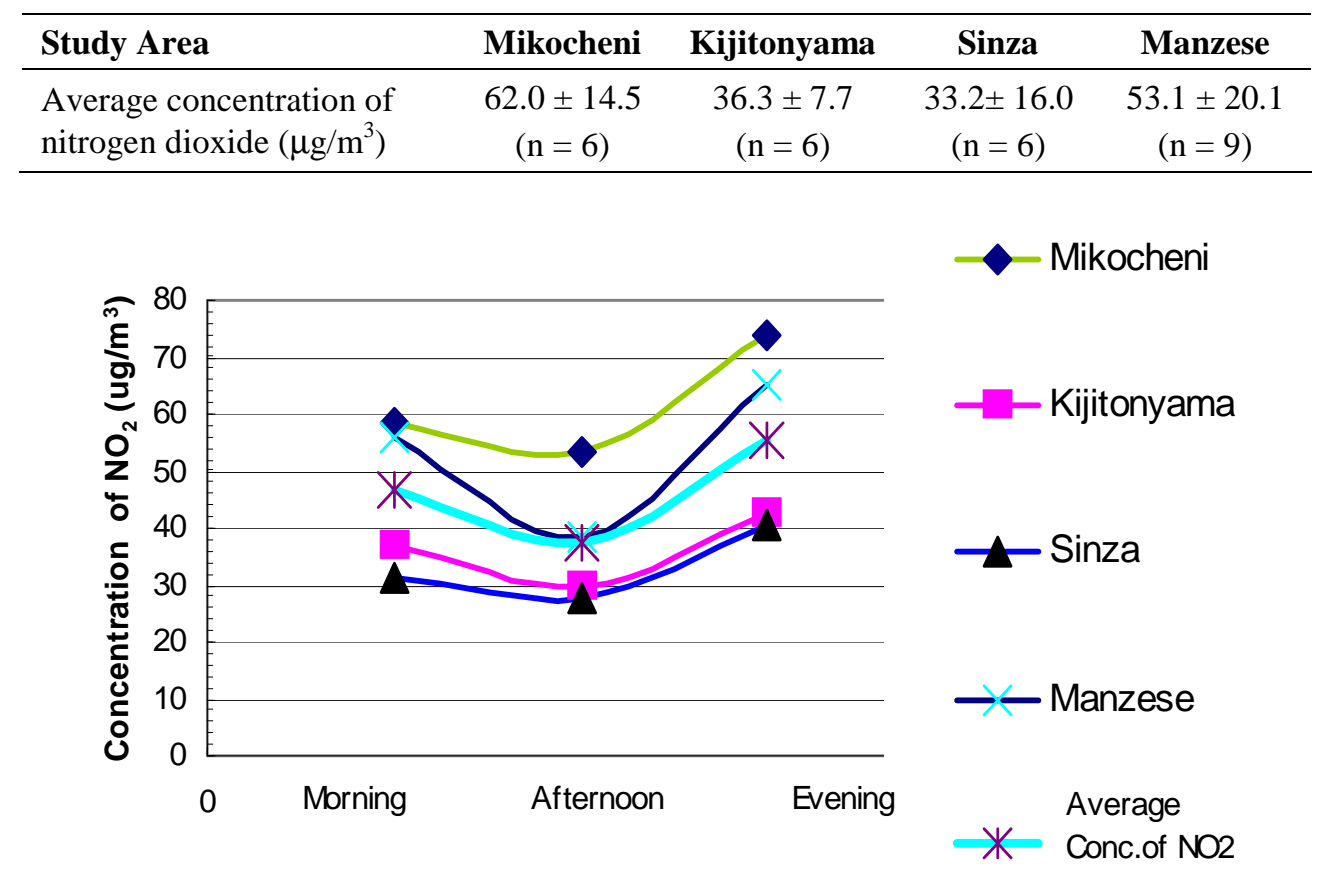

Figure 2: Average temporal variation of nitrogen dioxide concentration.

Table 2: Average concentration of SPM $\left(\mu \mathrm{g} / \mathrm{m}^{3}\right)$.

\begin{tabular}{lcccc}
\hline Study Area & Mikocheni & Kijitonyama & Sinza & Manzese \\
\hline Average concentration of SPM $\left(\mu \mathrm{g} / \mathrm{m}^{3}\right)$ & 419 & 631 & 804 & 728 \\
\hline
\end{tabular}

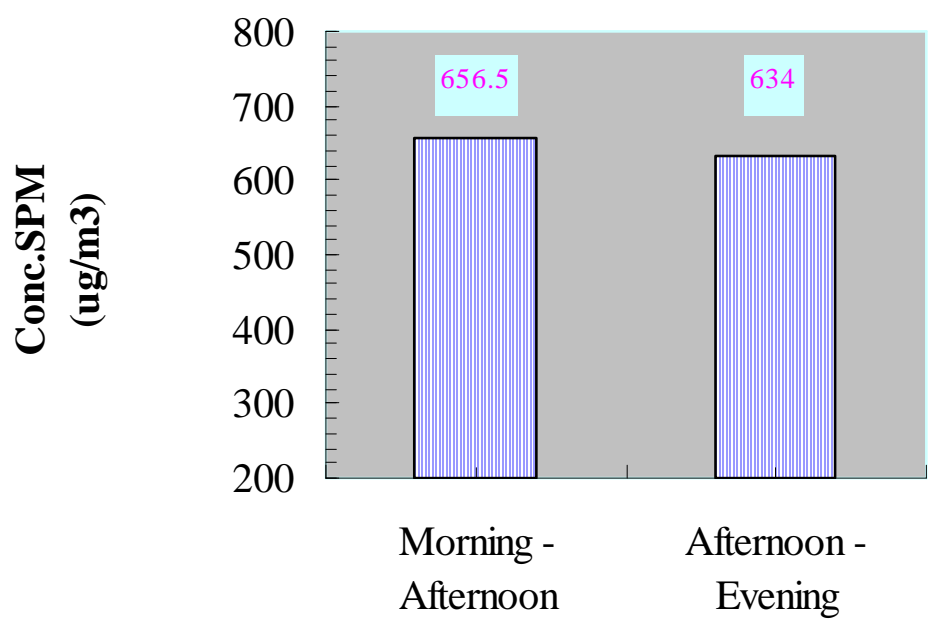

\section{Time interval}

Figure 3: Temporal average concentration of SPM. 


\section{Particulate lead $(\mathbf{P b})$}

The six hourly average lead concentration ranging from 9.04 to 12.03 $\mu \mathrm{g} / \mathrm{m}^{3}$ exceed the recommended WHO guidelines value of $1.5 \mu \mathrm{g} / \mathrm{m}^{3}$ (Figure 4) at all sampling sites. The overall average concentration of particulate lead for all the four sites is $10.6 \pm 1.8 \mu \mathrm{g} / \mathrm{m}^{3}$. The highest concentrations were observed at Sinza and Manzese areas while the lowest concentration was observed in Mikocheni area (Figure 4).

\section{Carcinogenic risk assessment}

Using equation 3.2 and data from figure 4, chronic daily intakes (CDI) for adult and children population were calculated. The CDI calculation is based on the average concentration as determined in this study. Risk characterization was done using slope factor of lead adopted from USEPA 1986 cancer guidelines as $4.2 \times 10^{-2} \mathrm{mg} / \mathrm{kg}$.day ${ }^{-1}$ and equation 3.1. Population additional risk due to lead exposure was obtained by using equation 3.3 and data from Table 4. Population data for individual Wards (sites) were obtained from a Census Report of 2002 and are presented in table 4.

The individual carcinogenic risk due to lead at all the study sites are presented in figure 5. Multiplying individual risk and the population (Table 4), it was found that about 48 adults out of 606767 adult population and 12 children out of 476746 children population in Kinondoni municipality might end-up getting cancer if exposed for 20 hours per day for 50 and 10 years respectively.

The carcinogenic risk due to lead at all the study sites is greater than the acceptable limit of $1 \times 10^{-6}$ (US-EPA) (Figure 5). People living at Manzese and Sinza are at more risk than people in other studied areas (Figure 5). Adults are observed to be at higher risk than children at all sites (Figure 5), this is due to the fact that, adults are exposed for a longer period of time (50 years) while the exposure duration for children is 10 years only (Table $3)$.

\section{DISCUSSION}

Nitrogen dioxide

The highest concentrations were observed in Mikocheni and Manzese areas while the lowest concentration was observed in Sinza area (Table 1). In most cases, the levels of these pollutants were higher in the morning and evening hours than in the afternoon hours.

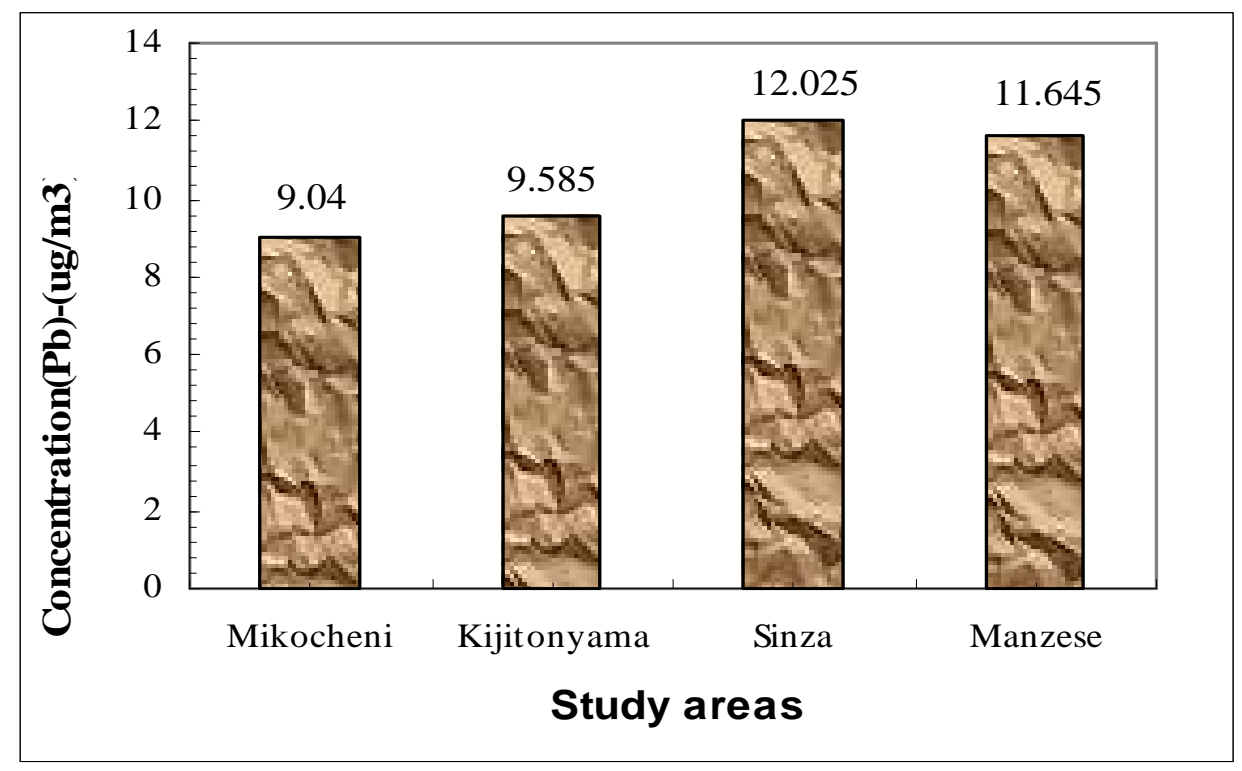

Figure 4: Average concentrations of $\mathrm{Pb}$ in the study areas. 
Table 3: Exposure parameters used to estimate doses for inhalation.

\begin{tabular}{|c|c|c|c|}
\hline Source & Case Parameters & Children's Scenario & Adults Scenario \\
\hline Assumption & $\begin{array}{l}\text { Age period } \\
(\mathrm{yrs})\end{array}$ & $0-14$ & 15 and above \\
\hline Assumption & $\begin{array}{l}\text { Exposure frequency } \\
\text { (wks/year) }\end{array}$ & 48 & 48 \\
\hline Assumption & $\begin{array}{l}\text { Exposure length } \\
\text { (years) }\end{array}$ & 10 & 50 \\
\hline \multirow[t]{2}{*}{ USEPA } & $\begin{array}{l}\text { Air inhalation rate } \\
\left(\mathrm{m}^{3} / \text { day }\right)\end{array}$ & 20 & 20 \\
\hline & $\begin{array}{l}\text { Body weight } \\
(\mathrm{kg})\end{array}$ & 44 & 70 \\
\hline USEPA & $\begin{array}{l}\text { Averaging time for carcinogens } \\
\text { (Years) }\end{array}$ & 70 & 70 \\
\hline Assumption & $\begin{array}{l}\text { Exposure duration } \\
\text { (hrs/day) }\end{array}$ & 20 & 20 \\
\hline
\end{tabular}

Table 4: Population and households.

\begin{tabular}{lcc}
\hline Site name & Population & Number of households \\
\hline Mikocheni & 47096 & 10624 \\
Kijitonyama & 27283 & 6200 \\
Sinza & 36469 & 7841 \\
Manzese & 66866 & 17685 \\
\hline
\end{tabular}

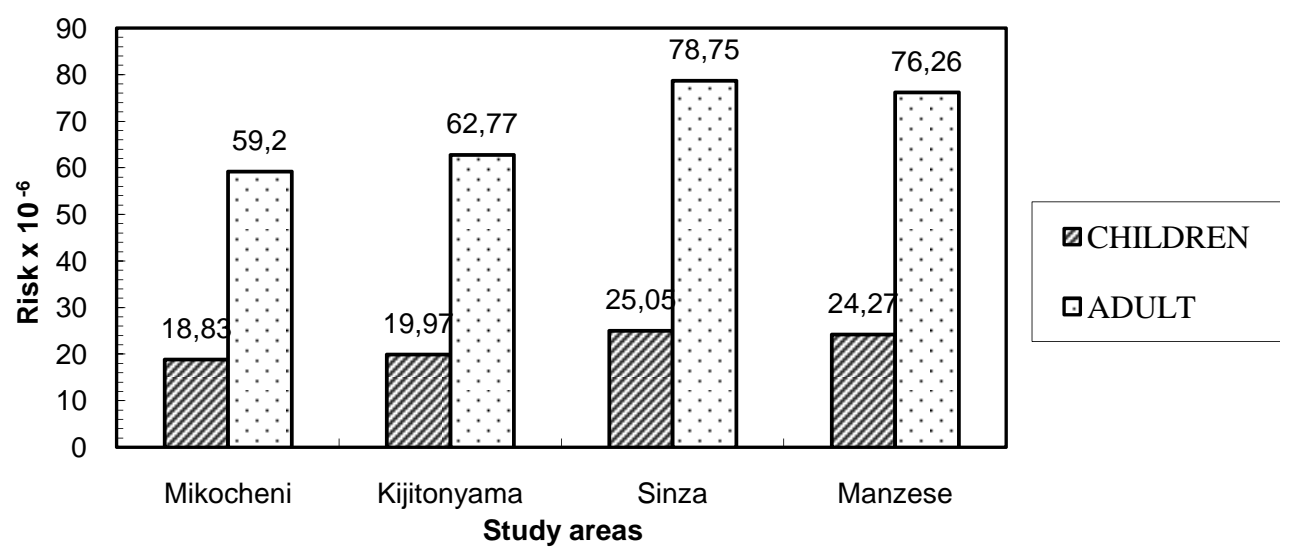

Figure 5: Carcinogenic risk at the study areas. 
Temporal variation of $\mathrm{NO}_{2}$ concentration during the day (Figure 2) tally with the activities producing this pollutant such as traffic flow. Higher concentrations are observed especially in the morning and evening when residents are moving from their homes to offices and vice versa. Traffic flow pattern with peaks in the morning and evening has been observed in another study (Jackson, 2005a) and this pattern is consistent with the observed temporal variation of $\mathrm{NO}_{2}$ in the current study. Beside emissions of $\mathrm{NO}_{2}$ from mobile sources, other activities, which may generate a small amount of $\mathrm{NO}_{2}$ include waste burning, some industrial processes, and cooking by using firewood. Waste burning is mostly undertaken in the evening. Generally it can be said that, activities pattern conforms to the observed $\mathrm{NO}_{2}$ level pattern (Figure 2). Photochemical reactions involving $\mathrm{NO}_{2}$ may also lead to reduction of $\mathrm{NO}_{2}$ in the afternoon hours (Finlayson-Pitts and Pitts, 1993)

Highest $\mathrm{NO}_{2}$ concentration is consistently observed at Mikocheni followed by Manzese. Kijitonyama and Sinza have low level of $\mathrm{NO}_{2}$. These observations may be explained by the presence of highways (Old Bagamoyo and Alli Hassan Mwinyi Roads) in the vicinity of Mikocheni and Morogoro Road which is running across Manzese. These express roads have high traffic volume, and a significant number of vehicles using these roads are diesel powered. Emissions from mobile sources could thus be a major contributor to $\mathrm{NO}_{2}$ at Mikocheni and Manzese. Use of firewood for cooking at Manzese and existence of an Industrial area at Mikocheni, could also be contributing to high levels of $\mathrm{NO}_{2}$ in these areas. The average concentration of Nitrogen dioxide observed in the four areas (Wards) ranging from 16 to 74 $\mu \mathrm{g} / \mathrm{m}^{3}$ is lower than the $\mathrm{NO}_{2}$ levels observed in Hongkong based on samples collected in 15 locations with $\mathrm{NO}_{2}$ levels ranging from 60 to $245 \mu \mathrm{g} / \mathrm{m}^{3} \quad$ (Environmental Protection Department, 1996). The hourly $\mathrm{NO}_{2}$ levels observed in a London study ranged from 100 to $400 \mu \mathrm{g} / \mathrm{m}^{3}$ (Seinfield, 1994), were also higher than levels observed in this study. High levels of $\mathrm{NO}_{2}$ in London and Hongkong compared to Dar es Salaam, in spite of the advancement in the application of cleaner technologies in these places, may be attributed to high traffic volumes and high level of industrialization compared to Tanzania. Nitrogen dioxide levels obtained in this study from residential sites are comparable with roadside $\mathrm{NO}_{2}$ levels established in the previous studies (Table 5) (Sosthness, 2002; Jackson 2005b; and Henricson, 1997). Bus station $\mathrm{NO}_{2}$ levels (Kamuzora, 2002) are fairly higher than residential areas $\mathrm{NO}_{2}$ levels observed in this study (Table 5). This observation might be explained by the fact that, at Bus Stations, a substantial amount of $\mathrm{NO}_{2}$ is emitted from combustion processes almost continuously.

\section{Suspended particulate matter (SPM) \\ The highest concentration was} observed at Sinza area with average concentration of $804.00 \mu \mathrm{g} / \mathrm{m}^{3}$ (Table 2). The observed high levels of SPM in Sinza Area could be attributed to un-tar roads (including Shekilango road) at Sinza area observed during the sampling period in year 2005, and the fact that this high density area is largely occupied by middle income people who own cars. The lowest average SPM level at 418.67 $\mu \mathrm{g} / \mathrm{m} 3$ was observed at Mikocheni area. Low SPM concentrations at this area could be attributed to several factors, including: tarmacadam main roads (Old Bagamoyo and Ally Hassan Mwinyi) in this area, medium to low density area whose dwellers belong to the high income bracket who normally own relatively low mileage and better maintained vehicles, existence of some tarred parking areas, and well-kept vegetation cover and grass lawn.

High traffic density during morning rush hours could explain the observed slightly high SPM levels during these hours (Figure $3)$. Activities in industries, construction sites, and garages, which are mainly done in the morning hours, also serve to explain high levels of SPM in the morning to afternoon hours. Moderate traffic density in the evening hours, as some people avoid traffic jam by delaying their return trips from offices till night hours could explain the observed low SPM levels.

Range of six hourly average SPM concentration obtained in this study for Kinondoni municipality in Dar es Salaam City is lower than ranges obtained in previous studies conducted in Dar es Salaam 
Table 5: Comparisons of $\mathrm{NO}_{2}$ concentrations from this study and levels from other studies.

\begin{tabular}{lcc}
\hline Nation / Organization & Nature of Site & $\begin{array}{c}\mathbf{N O}_{2} \text { Concentration } \\
\left(\boldsymbol{\mu g} / \mathbf{m}^{\mathbf{3}}\right) \text { Data Range }\end{array}$ \\
\hline Sosthness, 2003 & Road Junction & $26-53$ \\
Kamuzora, 2003 & Bus Station, Tanzania & $88.24-297.52$ \\
Jackson, 2005a & Roadside & $18-56$ \\
Henricson, 1997 & Roadside & $23-45$ \\
This study & Residential areas & $16-74$ \\
\hline
\end{tabular}

(Table 6). Previous studies were conducted on road junctions (Sosthness, 2003) and bus station (Kamuzora, 2003), while the current study was undertaken in a residential area. SPM levels obtained in this study are much higher than levels measured in London City and Hongkong (Table 6). Possible explanation for low SPM levels observed in London and Hongkong could be: tarmacadam roads and pavements in those cities, use of relatively clean energy sources for cooking such as natural gas and electricity, and adherence to strict emission standards (Table 6).

\section{Particulate lead $(\mathbf{P b})$}

Progressive decrease of lead concentrations in air with years (Table 7) may be a result of progressive decrease of lead levels in petrol with years and the subsequent phasing out of leaded petrol in 2004 by Tanzanian Government. Observed lead levels in this study point to the fact that petrol driven engines were not the only source of lead. Other sources include paint industry and industrial engine oils. The persistence of lead once it is in the environment also serve to explain the observed lead residue in the air in spite of the phasing out of leaded petrol (LaGraga, 1994). Possible loopholes in the implementation of the leaded petrol ban may also contribute to the observed lead in the air. Besides the phasing out of leaded petrol, the low lead concentrations from this study compared with lead levels established in the previous studies (Table 7) (University of Dares-Salaam (UDSM) Chemistry, 1993; Othman, 1994; and Sosthness, 2002), may be due to the fact that this study was conducted on the residential areas, where normally the traffic density is low, while the previous studies were conducted on roadsides and road junctions.

\section{Carcinogenic risk assessment}

The carcinogenic risk due to lead at all the study sites is greater than the acceptable limit of $1 \times 10^{-6}$ (US-EPA) (Figure 5). People living at Manzese and Sinza are at more risk than people in other studied areas (Figure 5). Adults are observed to be at higher risk than children at all sites (Figure 5), this is due to the fact that, adults are exposed for a longer period of time (50 years) while the exposure duration for children is 10 years only (Table $3)$.

\section{Conclusion}

The following conclusion can be drawn from this study:

Nitrogen hourly average concentration in Kinondoni municipality was below WHO hourly standard of $200 \mu \mathrm{g} / \mathrm{m}^{3}$. The overall average $\mathrm{NO}_{2}$ concentration in the study areas was $46.15 \pm 19.0 \mu \mathrm{g} / \mathrm{m}^{3}$.

The overall average concentration of suspended particulate matter in ambient air was $645.3 \pm 169.3 \mu \mathrm{g} / \mathrm{m}^{3}$, which was above the WHO standards of $230.00 \mu \mathrm{g} / \mathrm{m}^{3}$.

The overall average concentration of particulate lead for all the four sites was $10.6 \pm 1.8 \mu \mathrm{g} / \mathrm{m}^{3}$, which was above the WHO standards of $1.5 \mu \mathrm{g} / \mathrm{m}^{3}$.

The risk assessment was undertaken considering the people who spend most of their times in the residential areas. The unit risk realised was $78.75 \times 10^{-6}$ for adults and $25.05 \times 10^{-6}$ for children, both groups showing risk higher than the United States of America Environmental protection agency (USEPA) acceptable limit of $1 \times 10^{-6}$. Additional 
Table 6: Comparisons of SPM concentrations from this study with concentrations from other studies.

\begin{tabular}{lccc}
\hline Study & Country & Nature of Sites & $\begin{array}{c}\text { Concentrations range } \\
\left(\boldsymbol{\mu g} / \mathbf{m}^{\mathbf{3}}\right)\end{array}$ \\
\hline $\begin{array}{l}\text { Sosthenes, 2003 } \\
\text { Kamuzora, 2003 }\end{array}$ & Dar-es-Salaam & Road Junctions & $758-1343$ \\
Harrison, 1997 & Dar-es-Salaam & Bus Stations & $592.29-1211.30$ \\
$\begin{array}{l}\text { Environmental Protection } \\
\text { Department, 1996 }\end{array}$ & London, U.K. & Roadsides & $24.7-35.7$ \\
This study & HongKong & Roadsides & $50-260$ \\
\hline
\end{tabular}

Table 7: Comparisons of particulate lead concentrations from this study with results from other studies.

\begin{tabular}{lcc}
\hline Study & Nature of Sites & Data Range \\
\hline UDSM, Chemistry, 1993 & Roadsides & $20-76 \mu \mathrm{g} / \mathrm{m}^{3}$ \\
Othman, 1994 & Roadsides & $74-85 \mu \mathrm{g} / \mathrm{m}^{3}$ \\
Sosthenes, 2002 & Road Junctions & $8-36 \mu \mathrm{g} / \mathrm{m}^{3}$ \\
This Study, 2005 & Residential & $7.41-15.59 \mu \mathrm{g} / \mathrm{m}^{3}$ \\
\hline
\end{tabular}

population risk contributed by particulate lead was estimated to result in 48 cancer cases out of 606767 exposed adults and 12 cancer cases for children out of 476746 exposed children.

\section{Recommendations}

The following recommendations are made based on the findings of this study:

Strictly enforce the use of unleaded gasoline in the country. Regulate lead usage in paints production and importation, and also regulate lead usage in industrial oils and other industrial processes.

Create public awareness on the potential reduction of SPM pollution through tarring of private packing areas, pavements, and private roads. Public awareness on the importance of keeping of vegetation cover and grass lawn as a strategy towards SPM pollution reduction should be created.

Introduce regular road-cleaning schemes in urban centres to reduce the burden of suspended particulate matter (SPM) in the urban atmosphere.

A long term, country wide monitoring programme be mounted in order to establish the annual averages of urban pollutant levels in all urban centres in the country. This should include monitoring of SPM and particulate lead.

\section{REFERENCES}

Environmental Protection Department, 1996. Air quality in Hong Kong 1995 Report. Hong Kong Environmental Protection Department.

Harrison RM, Deacon AR, Jones MR. 1997. Sources and processes affecting concentrations of PM10 and PM2.5 particulate metter in Birmingham (UK). Atmospheric Environment, 31(24): 41034117.

Henricson D. 1997. Air pollution by road traffic in Dar-es-salaam: Measurement and state of art description. MSc Thesis, Royal Institute of Technology, Sweden.

Jackson MM. 2005a. Roadside concentration of gaseous and particulate matter pollutants and risk assessment in Dar-esSalaam, Tanzania. Journal of Environmental Monitoring and Assessment, 104: 385-407. 
Jackson MM. 2005b. Air pollution in Southern Africa: The case of motor vehicles exhaust contribution in Dar-esSalaam city. Journal of Building and Land Development, 12(1-3): 1-19.

Jackson MM, Semiono P. 2005. Indoor air pollution from combustion of cooking Fuelwood, Charcoal and Kerosene, Proc. of IET Conference, Arusha, Tanzania, $1^{\text {st }}-2^{\text {nd }}$ Dec.

Kamuzora M. 2003. Assessment of air pollution at bus stations in Dar-esSalaam, BSc (Env. Eng.) Thesis, University College of Lands and Architectural Studies (UCLAS), Tanzania.

Klonoff-Cohen H, Lam PK, Lewis. A. 2005. Outdoor carbon monoxide, nitrogen dioxide, and sudden infant death syndrome. Archives of Diseases in Childhood, 90: 750 - 753

LaGrega MD, Buckingham PL, Evans JC. 1994. Hazardous Waste Management. Publisher McGraw-Hill: Inc. NY.

National Census Report. 2002. Bureau of Statistics, Tanzania.
Finlayson-Pitts BJ, Pitts JN. 1993. Atmospheric chemistry of tropospheric ozone formation: Scientific and regulatory implications. Journal of Air and Waste, 43: 1091-1100.

Seinfeld JH. 1986. Atmospheric Chemistry and Physics of Air Pollution. John Wiley and Sons Inc: New York.

Sosthness R. 2003. Traffic air pollution at road junctions in Dar-es-Salaam, BSc (Env. Eng.) Thesis, University College of Lands and Architectural Studies (UCLAS), Tanzania.

University of Dar-es-salaam (UDSM), chemistry department. 1993. Urban air quality monitoring. Pilot Project, National Environmental Management Council, Dar-es-salaam.

WHO. 1987. Air Quality Guidelines for Europe. WHO Regional Publications, European Series No.23.

WHO. 1976. Selected Methods of Measuring Air Pollutants. WHO Publications: Geneva. 